\title{
The morphology of oxygen greenline dayglow emission
}

\author{
S. Tyagi and V. Singh \\ Department of Physics, University of Roorkee, Roorkee-247667, India \\ Received: 10 October 1997 / Revised: 6 February 1998 / Accepted: 12 May 1998
}

\begin{abstract}
In this study, the morphology of the oxygen greenline dayglow emission is presented. The volume emission rate profiles are obtained by using Solomon's glow model. The glow model is updated in terms of recent cross sections, reaction rate coefficients and quantum yield of greenline emission. Throughout most of the thermosphere the modelled and observed emission rates are in reasonably good agreement. In the region between 98 and $120 \mathrm{~km}$, the modelled emission rates are substantially higher (about a factor of 1.7) than the observed emission rates. This discrepancy is discussed in terms of scaling of solar fluxes which accounts the variation of solar activity for the day on which calculations are made. The modelled morphology of greenline emission is compared with those cases where WINDII data is available. The modelled and observed morphology is in reasonably good agreement at most of the latitudes above $120 \mathrm{~km}$. In the mesosphere the qualitative nature of morphology is very similar to those of WINDII observation except the modelled emission rates are about a factor of 1.7 higher than the observed emission rates.
\end{abstract}

Keywords. Ionosphere (ion chemistry and composition; modeling and forecasting; solar radiation and cosmic ray effects).

\section{Introduction}

In the recent years lot of attention has been paid to study the $\mathrm{O}\left({ }^{1} \mathrm{~S}\right)$ dayglow emission (Singh and Tyagi 1997; Singh et al., 1996 Torr et al., 1993; Bates 1990; Akmaev and Shved 1980., Frederick et al., 1976;

Correspondence to: V. Singh
Feldman et al., 1971; Wallace and McElroy, 1966). This emission provides the information about the variability of solar activity and atomic oxygen concentration in upper mesosphere and the thermosphere. The visible airglow experiment (VAE) on board atmosphere explorer (AE-C) satellite (Hays et al., 1973) has provided valuable data for this emission in dayglow. Recently, the wind imaging interferometer (WINDII) (Shepherd et al., 1993 on board the Upper Atmosphere Research Satellite (UARS) has provided extensive data which can be used to study the morphology of greenline emission in day time. A unique feature of the WINDII instrument is that it has provided the first comprehensive set of measurements of the dayglow greenline emission throughout the 80 to $300 \mathrm{~km}$ region between $50^{\circ} \mathrm{S}$ and $50^{\circ} \mathrm{N}$ geographic latitudes. Solheim et al., (1993) have presented the morphology of greenline dayglow emission by using WINDII observations for some special cases. The morphological study of atomic oxygen greenline emission in day time is of great importance because it would provide information about the transport of atomic oxygen. The regions of tides can also be identified from the morphology of greenline dayglow emission. Consequently, there is a need to develop a more comprehensive model so that one may present a more realistic picture of greenline dayglow emission.

Here we present the morphology of atomic oxygen greenline dayglow emission which is obtained using the glow model of Solomon (1992). The glow model is updated by using more recent cross section data, reaction rate coefficients and variation of solar fluxes. The modelled morphology of greenline emission is compared with those cases where WINDII data is available.

\section{Model}

Mechanisms for the production of greenline dayglow emission have been discussed by several authors (Nardi 1991; Bates 1990; Zipf 1988; Frederick et al., 1976; Lawrence and McEwan 1973; Hays and Sharp 1973; 
Wallace and McElroy 1966). The following reactions have been identified as sources of greenline emission in dayglow.

Photoelectron impact excitation of atomic oxygen.

$\mathrm{O}\left({ }^{3} \mathrm{P}\right)+\mathrm{e}_{\mathrm{ph}} \rightarrow \mathrm{O}\left({ }^{1} \mathrm{~S}\right)+\mathrm{e}_{\mathrm{ph}}$

Dissociative recombination of $\mathrm{O}_{2}^{+}$

$\mathrm{O}_{2}^{+}+\mathrm{e}_{\text {th }} \rightarrow \mathrm{O}\left({ }^{1} \mathrm{~S}\right)+\mathrm{O}$

Energy transfer to atomic oxygen from $\mathrm{N}_{2}\left(\mathrm{~A}^{3} \Sigma_{\mathrm{u}}^{+}\right)$

$\mathrm{N}_{2}+\mathrm{e}_{\mathrm{ph}} \rightarrow \mathrm{N}_{2}\left(\mathrm{~A}^{3} \Sigma_{\mathrm{u}}^{+}\right)+\mathrm{e}_{\mathrm{ph}}$

$\mathrm{N}_{2}\left(\mathrm{~A}^{3} \Sigma_{\mathrm{u}}^{+}\right)+\mathrm{O}\left({ }^{3} \mathrm{P}\right) \rightarrow \mathrm{N}_{2}+\mathrm{O}\left({ }^{1} \mathrm{~S}\right)$

Photodissociation of molecular oxygen by solar EUV photons.

$\mathrm{O}_{2}+\mathrm{h} v\left(\lambda<1332.5 \mathrm{~A}^{\circ}\right) \rightarrow \mathrm{O}+\mathrm{O}\left({ }^{1} \mathrm{~S}\right)$

Three body recombination of atomic oxygen (Barth, 1964).

$\mathrm{O}\left({ }^{3} \mathrm{P}\right)+\mathrm{O}\left({ }^{3} \mathrm{P}\right)+\mathrm{M} \rightarrow \mathrm{O}_{2}^{*}+\mathrm{M}$

$\mathrm{O}_{2}^{*}+\mathrm{O}\left({ }^{3} \mathrm{P}\right) \rightarrow \mathrm{O}_{2}+\mathrm{O}\left({ }^{1} \mathrm{~S}\right)$

where $\mathrm{O}_{2}^{*}$ represents an unidentified excited state of molecular oxygen possibly $\mathrm{O}_{2}\left(\mathrm{~A}^{3} \Sigma_{\mathrm{u}}^{+}\right), \mathrm{O}_{2}\left(\mathrm{~A}^{\prime 3} \Delta_{\mathrm{u}}\right)$, $\mathrm{O}_{2}\left(\mathrm{c}^{1} \Sigma_{\mathrm{u}}^{-}\right)$or $\mathrm{O}_{2}\left({ }^{5} \Pi_{\mathrm{g}}\right)$.

The glow model as developed by Solomon (1992) is used in the present calculations. We have included all the possible known sources of $\mathrm{O}\left({ }^{1} \mathrm{~S}\right)$ production as discussed already. The atmospheric neutral densities and neutral temperatures have been used from MSIS-90 neutral model atmosphere (Hedin, 1991). We have updated the Glow Model by using more appropriate $\mathrm{O}$ excitation and ionization cross sections, as given by Kanik et al. (1993). Above $30 \mathrm{eV}$, these new cross sections are about a factor of 1.5 smaller than the cross sections used by Richards and Torr (1983). The total electron impact cross sections for $\mathrm{O}$ have been modified by taking into account the new $\mathrm{O}\left({ }^{1} \mathrm{D}\right)$ cross sections of Laher and Gilmore (1990).

The transport of photoelectrons (Nagy and Banks, 1970) and conjugate point effects (Banks and Nagy, 1970) have been included in the calculations. The solar flux values used in the calculations are based on the full F74113 reference solar spectrum of Hinteregger (1977) which is scaled using parametrization method based on F10.7 (daily $10.7 \mathrm{~cm}$ solar flux) and F10.7A (81 days average $10.7 \mathrm{~cm}$ solar flux). For ionizing EUV, the bin structure method of Torr and Torr (1985) is used. The following equations are used for the scaling of solar flux.

$$
\begin{aligned}
\text { SFLUX }= & {\left[\operatorname{RFLUX}+\left\{\left(R_{1}-1\right)\right.\right.} \\
& \left.\left.\times S_{1}+\left(R_{2}-1\right) \times S_{2}\right\} / 1000\right]
\end{aligned}
$$

where:

SFLUX is scaled solar flux,

$R F L U X$ is reference solar flux,

$S_{1} \quad$ are scaling factors for solar Lyman $\beta$ (1026 $\mathrm{A}^{\circ}$ ) chromospheric emission,
$S_{2} \quad$ are scaling factors for $\mathrm{Fe}(\mathrm{XVI})$ coronal emission $\left(335 \mathrm{~A}^{\circ}\right)$,

$$
\begin{aligned}
R_{1}= & 1+0.0138 \times(\mathrm{F} 10.7 \mathrm{~A}-71.5)+0.005 \\
& \times(\mathrm{F} 10.7-\mathrm{F} 10.7 \mathrm{~A}+3.9) \\
R_{2}= & 1+0.59425 \times(\mathrm{F} 10.7 \mathrm{~A}-71.5)+0.3811 . \\
& \times(\mathrm{F} 10.7-\mathrm{F} 10.7 \mathrm{~A}+3.9)
\end{aligned}
$$

There are 59 values for each of $S_{1}$ and $S_{2}$ which correspond to 59 bins of solar spectrum (the values of $S_{1}$ and $S_{2}$ are given in subroutine SSFLUX of the glow model).

Singh et al. (1996) have used the simple linear scaling of solar flux using the following expression

SFLUX $=$ RFLUX $\times \mathrm{F} 10.7 / 70$

The scaling of solar spectrum in the present model is better than the scaling of Singh et al. (1996) because it accounts for the variation in solar flux more precisely in two regions of spectrum in the vicinity of $1026 \mathrm{~A}^{\circ}$ and $335 \mathrm{~A}^{\circ}$. The first region near $1026 \mathrm{~A}^{\circ}$ is important for the photodissociation of $\mathrm{O}_{2}$ which results in production of $\mathrm{O}\left({ }^{1} \mathrm{~S}\right)$ (reaction 5).

The quantum yield of $\mathrm{O}\left({ }^{1} \mathrm{~S}\right)$ from dissociative recombination of $\mathrm{O}_{2}^{+}$has been the subject of some discussion in recent years (Takahashi et al., 1990; Bates, 1990; Yee et al., 1989; Zipf., 1988; Guberman, 1987; Yee and Killeen, 1986; Bates and Zipf, 1980). The effective recombination coefficient for this process depends on various parameters such as the vibrational distribution of the $\mathrm{O}$ ion, the thermal electron temperature and the electron to neutral density ratio $n(\mathrm{e}) / n(\mathrm{O})$, Yee and Killeen (1986) have reported that quantum yield of $\mathrm{O}\left({ }^{1} \mathrm{~S}\right)$ from the dissociative recombination of $\mathrm{O}_{2}^{+}$in the vibrational levels $v=1$ and 2 may vary between 0.09 and 0.23 . Bates (1990) further reviewed the quantum yield problem, and, on the basis of that work, we divide the altitude region of interest into three parts each with a different value for the $\mathrm{O}\left({ }^{1} \mathrm{~S}\right)$ quantum yield. For the altitude region upto $120 \mathrm{~km}$ we have used a quantum yield of 0.1 , between 120 and $140 \mathrm{~km}$ we used a value of 0.12 and above $140 \mathrm{~km}$ we adopted a value of 0.165 . These values are found more appropriate to explain WINDII observations (Singh et al., 1996). The $\mathrm{N}_{2}\left(\mathrm{~A}^{3} \Sigma_{u}^{+}\right)$excitation cross sections are taken from the work of Trajmar et al. (1983). The $\mathrm{O}\left({ }^{1} \mathrm{~S}\right)$ production rates due to the $\mathrm{N}_{2}\left(\mathrm{~A}^{3} \Sigma_{u}^{+}\right)$transfer reaction and dissociative recombination of $\mathrm{O}_{2}^{+}$are calculated using steadystate kinetics and the relevant reaction rate coefficients (Singh et al., 1996). Piper (1982) has measured a value of 0.75 for transfer from the $v=0$ level of $\mathrm{N}_{2}\left(\mathrm{~A}^{3} \Sigma_{u}^{+}\right)$, however, studies of $\mathrm{O}\left({ }^{1} \mathrm{~S}\right)$ production in the aurora and airglow (McDade et al., 1985; Gattinger et al., 1985; Abreu and Yee, 1991) have suggested that a value of 0.75 is not appropriate for the other vibrational levels. We have therefore summed the $\mathrm{N}_{2}\left(\mathrm{~A}^{3} \Sigma_{u}^{+}\right)$populations over the vibrational manifold and treated $\mathrm{O}\left({ }^{1} \mathrm{~S}\right)$ quantum yield from energy transfer to atomic oxygen from $\mathrm{N}_{2}\left(\mathrm{~A}^{3} \Sigma_{u}^{+}\right)$produced by photoelectron impact on molecular nitrogen as a variable parameter in glow model. 
Singh et al. (1996) have discussed some implications of $\mathrm{O}\left({ }^{1} \mathrm{~S}\right)$ production due to photodissociation of $\mathrm{O}_{2}$ by solar Lyman alpha. However, the results of this process are still uncertain due to nonavailability of a reliable quantum yield parameter. If one can assume this process is a source of $\mathrm{O}\left({ }^{1} \mathrm{~S}\right.$ ) with quantum yield of 0.012 (not verified) then it may yield emission below $96 \mathrm{~km}$ and may be a dominant source below $92 \mathrm{~km}$ (Singh et al., 1996). Consequently, due to these uncertainties in quantum yield parameter we have not included Lyman alpha in reaction 5 . The photoabsorption cross sections and quantum yields for wavelengths $\left(950 \mathrm{~A}^{\circ}-1200 \mathrm{~A}^{\circ}\right)$ are used from the work of Lawrence and McEwan (1973).

The $\mathrm{O}\left({ }^{1} \mathrm{~S}\right)$ production rates due to the three body recombination process are calculated using the excitation parameters of McDade et al. (1986) which were obtained from simultaneous rocket measurements of greenline night glow and atomic oxygen densities.

Having calculated the total $\mathrm{O}\left({ }^{1} \mathrm{~S}\right)$ production rates from the various sources discussed, the volume emission rates of greenline are obtained by taking into account all $\mathrm{O}\left({ }^{1} \mathrm{~S}\right)$ loss processes as used by Singh et al. (1996). All the relevant chemical reactions and rate coefficients are given in Table 1 .

\section{Results and discussion}

For the purpose of examining how the present results of greenline dayglow emission rates can explain the WINDII measurements, we have selected a set of volume emission rate profiles, calculated at various latitudes, during the months of January, April and May 1993. The modelled and measured emission rates are compared in Fig. 1 along with the earlier results of Singh et al. (1996). The individual components of $\mathrm{O}\left({ }^{1} \mathrm{~S}\right)$ production are also shown in this figure. It is noticeable from the profiles shown in Fig. 1 that the present results are in reasonably good agreement with the WINDII observation above $120 \mathrm{~km}$. It can also be noted that the earlier modelled results of Singh et al. (1997) and the present results are also in good agreement (within 15\%) above $120 \mathrm{~km}$. For the case of April 2, 1993 we do not have Singh et al. (1986) model emission rates for comparison with the present results. The altitudes of the F-region peak as obtained in the present model generally agree with the observed peak. As far as the individual components are concerned, the photoelectron impact on atomic oxygen, energy transfer from $\mathrm{N}_{2}\left(\mathrm{~A}^{3} \Sigma_{u}^{+}\right)$and dissociative recombination of $\mathrm{O}_{2}^{+}$are the important sources of $\mathrm{O}\left({ }^{1} \mathrm{~S}\right)$ above $120 \mathrm{~km}$. The contributions of the first two sources to $\mathrm{O}\left({ }^{1} \mathrm{~S}\right)$ are slightly less than (about 15\%) those obtained by Singh et al. (1996). This difference is mainly due to the transport of photoelectrons which was not included by Singh et al. (1996).

It is evident from Fig. 1 that contribution of dissociative recombination process is greater than from the photoelectron impact excitation of atomic oxygen at all altitudes in the thermosphere. It is well known that above $200 \mathrm{~km}$ the photoelectron impact excitation of atomic oxygen is a dominating source of $\mathrm{O}\left({ }^{1} \mathrm{~S}\right)$ in the dayglow. Therefore, the present model overestimates the emission rates due to dissociative recombination process above $200 \mathrm{~km}$. This discrepancy can be explained on the basis of $\mathrm{O}_{2}^{+}$and thermal electron densities in thermosphere. The glow model divides altitude into two segments for the calculation of electron densities. Below $200 \mathrm{~km}$ the electron densities and $\mathrm{O}_{2}^{+}$densities are calculated simultaneously using quadratic equations and are compatible with each other as can be seen in Figs. 2 and 3. Above $200 \mathrm{~km}$ the glow model uses electron densities from International Reference Ionosphere (IRI) (Bilitza, 1986) and $\mathrm{O}_{2}^{+}$densities are calculated by using quadratic equations which are not quite compatible with each other as can be seen in Figs. 2, 3. Consequently, a discontinuity exists at $200 \mathrm{~km}$. The electron density above $200 \mathrm{~km}$ cannot be obtained using quadratic equations because the transport and diffusion effects become very important at these altitudes (for more details the readers are refered to glow model). Further, if $\mathrm{O}_{2}^{+}$densities are also used from IRI model above 200 $\mathrm{km}$ in the present model the emission rates would decrease substantially and the agreement between the present results and the WINDII observations would further improve. In the region between 98 and $120 \mathrm{~km}$, the present calculated emission rates are substantially larger than the WINDII observations for all cases. The present emission rates are about a factor of 1.7 larger than the observed values at mesospheric peak. Between 98 and $120 \mathrm{~km}$ the only major source of $\mathrm{O}\left({ }^{1} \mathrm{~S}\right)$ production is photodissociation of molecular oxygen (as is evident from Fig. 1). The earlier results of Singh et al. (1996) for this process give much smaller values of emission rate than those of present emission rates. We have examined this difference between two models by comparing the solar fluxes which have been used to

Table 1 Reactions and rate coefficients

\begin{tabular}{lll}
\hline Reaction & Rate coefficient $\left(\mathrm{cm}^{-4} \mathrm{~s}^{-1}\right)$ & Reference \\
\hline $\mathrm{O}_{2}^{+}+\mathrm{e} \rightarrow \mathrm{O}\left({ }^{1} \mathrm{~S}\right)+\mathrm{O}\left({ }^{3} \mathrm{P}\right)$ & $1.6 \times 10^{-7}\left(300 / \mathrm{T}_{e}\right)^{0.5}$ & Walls and Dunn $(1974)$ \\
$\mathrm{N}_{2}\left(\mathrm{~A}^{3} \Sigma_{u}^{+}\right)+\mathrm{O}\left({ }^{3} \mathrm{P}\right) \rightarrow \mathrm{N}_{2}+\mathrm{O}\left({ }^{1} \mathrm{~S}\right)$ & $2.8 \times 10^{-11}$ & Piper et al. $(1981)$ \\
$\mathrm{O}\left({ }^{1} \mathrm{~S}\right)+\mathrm{O}_{2} \rightarrow \mathrm{O}\left({ }^{3} \mathrm{P}\right)+\mathrm{O}_{2}$ & $4.0 \times 10^{-12} \exp \left(-865 / \mathrm{T}_{n}\right)$ & Slanger et al. $(1972)$ \\
$\mathrm{O}\left({ }^{1} \mathrm{~S}\right)+\mathrm{O} \rightarrow \mathrm{O}\left({ }^{3} \mathrm{P}\right)+\mathrm{O}$ & Slanger and Black $(1976)$ \\
$\mathrm{O}\left({ }^{1} \mathrm{~S}\right)+\mathrm{O}_{2}\left(\mathrm{a}^{1} \Delta_{g}\right) \rightarrow \mathrm{O}\left({ }^{3} \mathrm{P}\right)+\mathrm{O}_{2}$ & $2 \times 10^{-14}$ & Kenner and Ogryzlo $(1982)$ \\
$\mathrm{O}\left({ }^{1} \mathrm{~S}\right) \stackrel{\mathrm{A}_{1}}{\rightarrow} \mathrm{O}\left({ }^{1} \mathrm{D}\right)+\mathrm{h} v(5577 \mathrm{~A})$ & $2.6 \times 10^{-10}$ & Nicolaides et al. $(1971)$ \\
$\mathrm{O}\left({ }^{1} \mathrm{~S}\right) \stackrel{\mathrm{A}{ }_{2}}{\rightarrow} \mathrm{O}\left({ }^{3} \mathrm{P},{ }^{1} \mathrm{D}\right)+\mathrm{h} v($ total $)$ & $\mathrm{A}_{1}=1.18 \mathrm{~s}^{-1}$ & Nicoladies et al. $(1971)$ \\
\hline
\end{tabular}



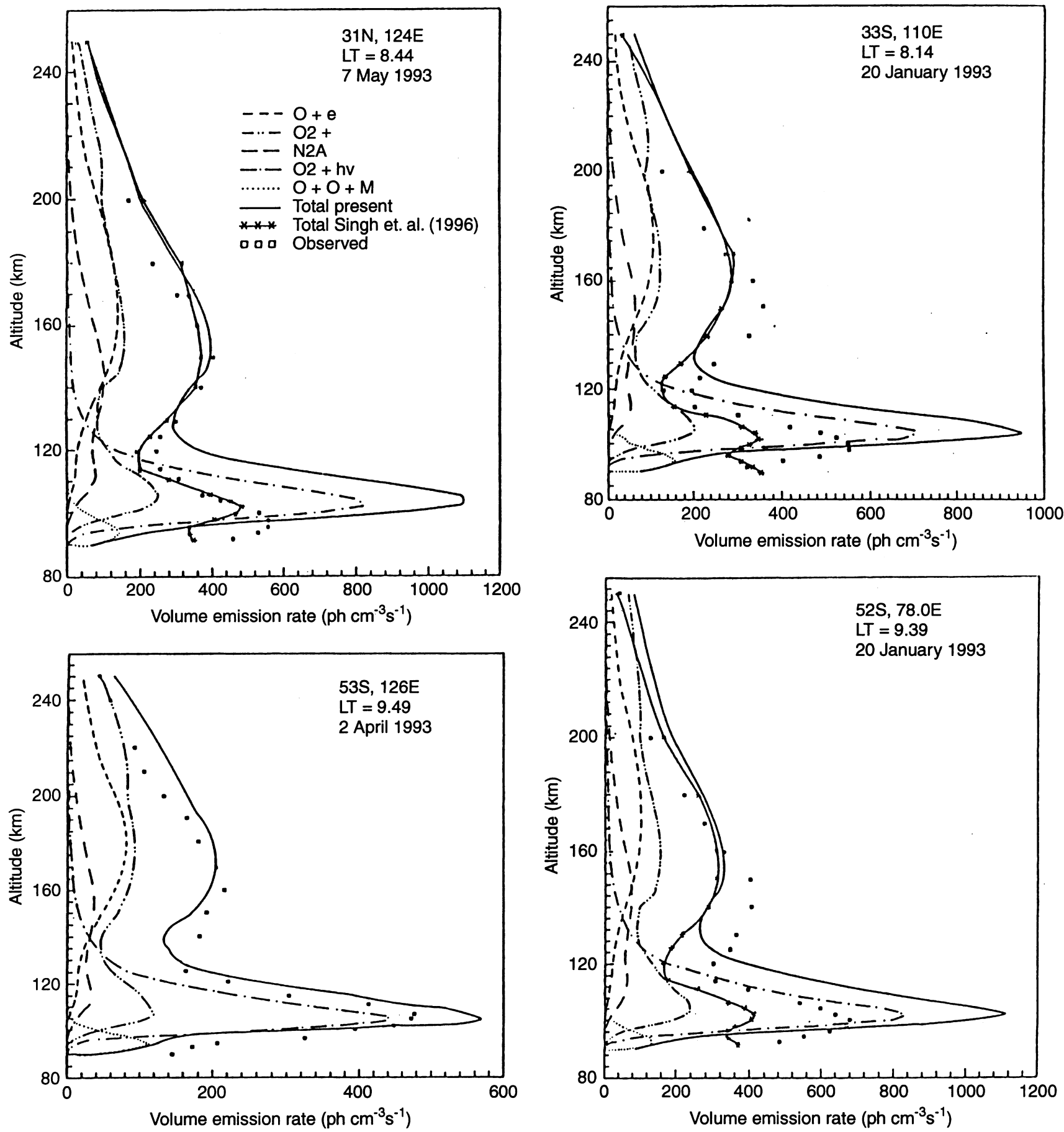

Fig. 1. Modelled and measured greenline dayglow emission profiles for selected observing (WINDII) conditions alongwith the various contributions of $\mathrm{O}\left({ }^{1} \mathrm{~S}\right)$ production processes

calculate $\mathrm{O}\left({ }^{1} \mathrm{~S}\right)$ emission rate due to photodissociation of $\mathrm{O}_{2}$. The solar fluxes used by Singh et al. (1996) between $950 \mathrm{~A}$ and $1175 \mathrm{~A}$ are about a factor of 2 to 3 times smaller than the fluxes which have been used in the present model. The reason for this discrepancy is scaling of solar fluxes for different solar activities. The solar flux values used by Singh et al. (1996) in their calculations were based on the full F74113 solar spectrum of Hinteregger (1977) and were linearly scaled (Eq. 9) using the F10.7 radio fluxes measured on the day of each set of WINDII observations. Although, the present model also uses the full F74113 reference solar spectrum of Hinteregger (1977) but the scaling procedure (Eq. 8) is quite different from that of Singh et al. (1986). The present scaling gives larger values of solar fluxes than those used by Singh et al. (1996). Consequently, the present emission rates due to photodissociation of $\mathrm{O}_{2}$ are about a factor of 3 larger than those of Singh et al. (1996) as shown in Fig. 4. Similar results have also been found for other cases. Further, it is quite clear from the 


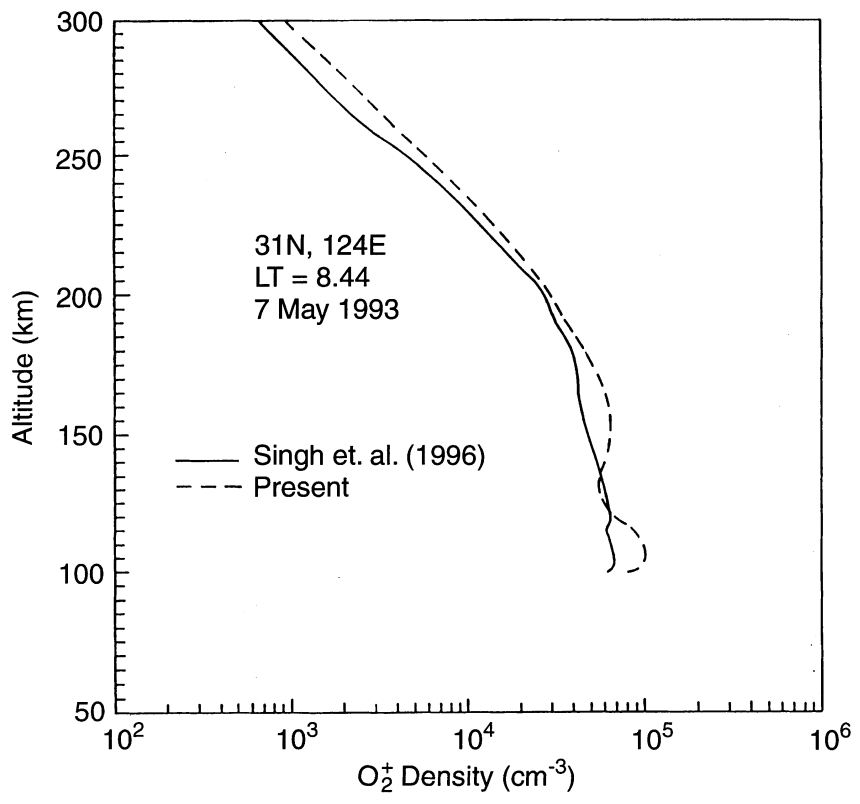

Fig. 2. Relative variation of $\mathrm{O}_{2}^{+}$densities obtained from the present model and IRI-86 model

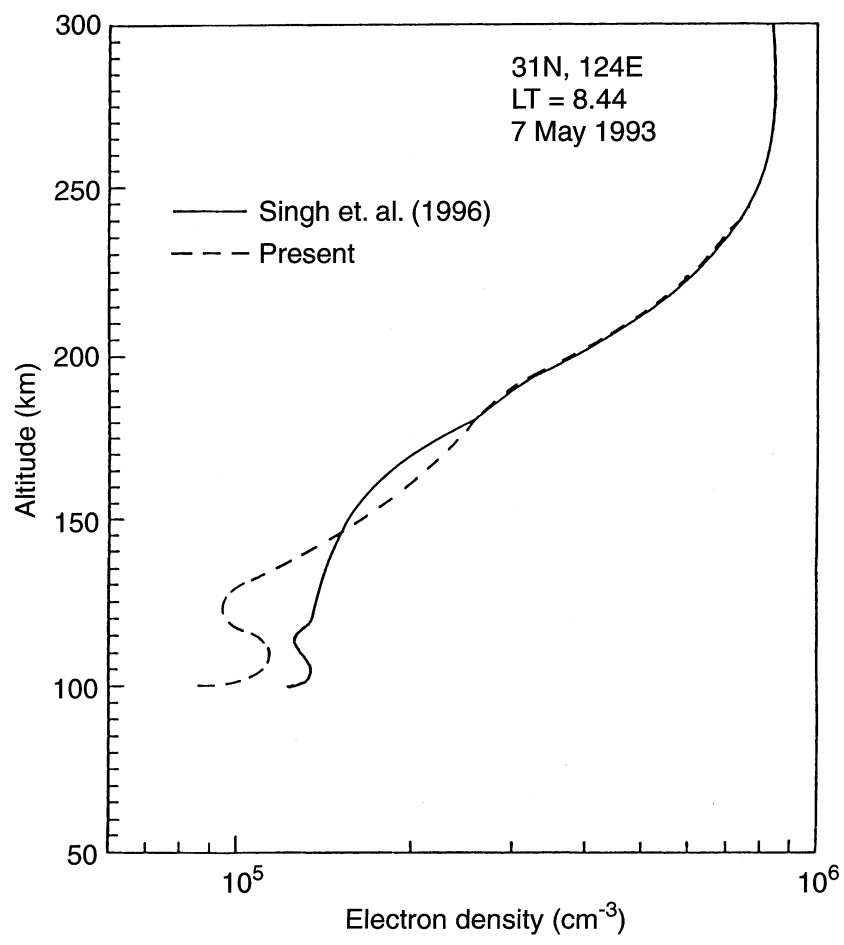

Fig. 3. Relative variation of electron densities obtained from the present model and IRI-86 model

Fig. 1 that neither present model nor the Singh et al. (1996) model could explain the WINDII observations in the region between 98 and $120 \mathrm{~km}$. The main problem for this discrepancy arises from the scaling of solar fluxes. This problem can only be resolved if the simultaneous measurements of solar fluxes are available for the day on which measurements have been taken for $\mathrm{O}\left({ }^{1} \mathrm{~S}\right)$ dayglow emission. We should mention here that

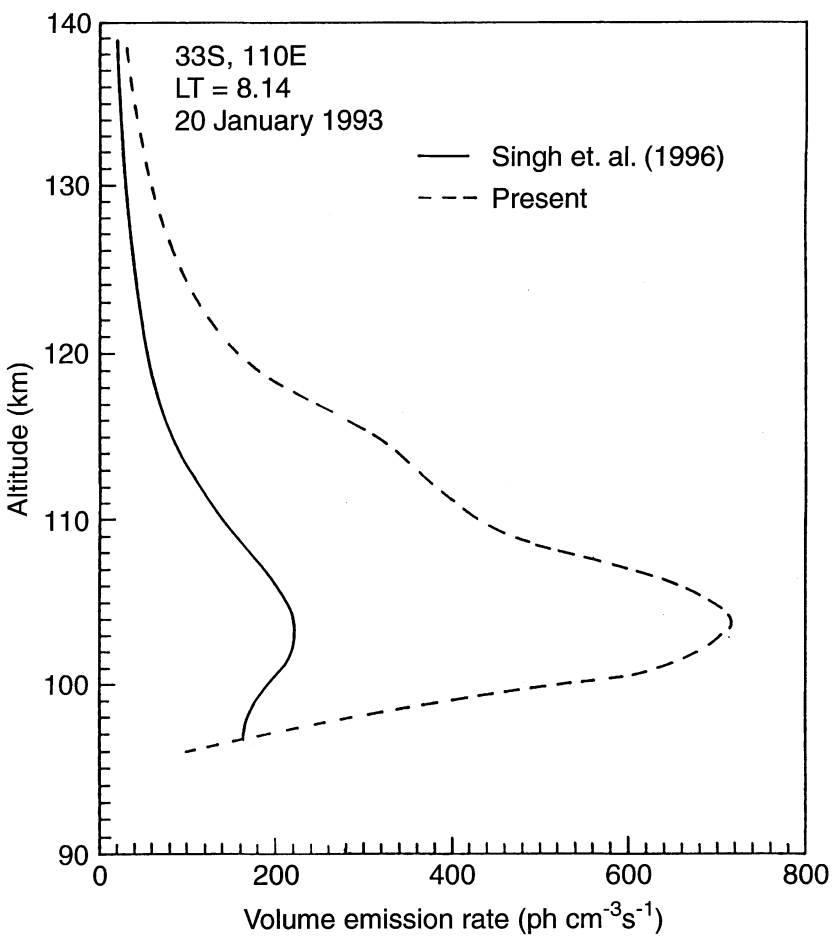

Fig. 4. Relative variation of greenline dayglow emission rates obtained from the present model and Singh et al. (1996) model for the photodissociation of $\mathrm{O}_{2}$

the qualitative nature of emission rates obtained from both models is very similar to those observed by WINDII in this region. Consequently, a suitable correction factor to either model may reproduce the observed emission rates between 98 and $120 \mathrm{~km}$. Between 90 and $98 \mathrm{~km}$ three body recombination process is the only major source of greenline emission. It is noticeable from Fig. 1 that the measured emission rates are substantially larger than the modelled emission rates in all cases. The present model also uses the same procedure to calculate emission rates due to three body recombination process as used by Singh et al. (1996). This discrepancy has already been discussed by Singh et al. (1996) and is quite likely due to failure of the MSIS-90 model to reproduce the oxygen atom densities in this region.

The comparison of the modelled emission rates with the WINDII observations, as discussed, clearly shows that the present model can be used to study the morphology of greenline dayglow emission. For the purpose of examining the extent to which the morphology obtained from WINDII data can be explained by the present model, we could only use two cases of WINDII for the comparison purpose. These cases are for the months of December, 1992/January/February/ 1993 and March/April 1993 at $10 \mathrm{~h}$ local time. Figures 5 and 6 show the comparison of measured and modelled volume emission rates for the months of December, 1992 to February 1993. From these figures it is noticeable that measured and modelled volume emission rates are in reasonably good agreement at thermospheric altitudes. However, in the mesosphere, present modelled emission rates are higher (as discussed earlier) than the 
Local time $=10.00($ December/January/February 1993)

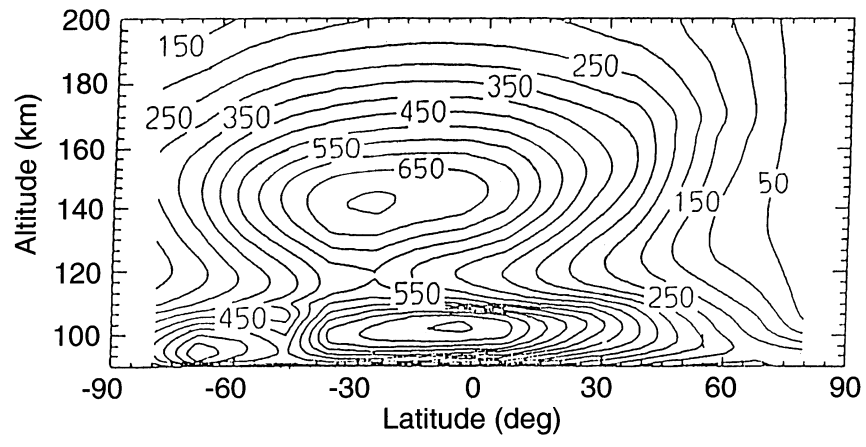

Fig. 5. The latitudinal variation of three monthly (December 1992/ January/February 1993) averaged volume emission rates as measured by wind imaging interferometer (WINDII) at $10 \mathrm{~h}$ local time (courtesy of Prof. G. G. Shepherd, York University, Canada)

Local time $=10.00$ (December/January/February 1993)

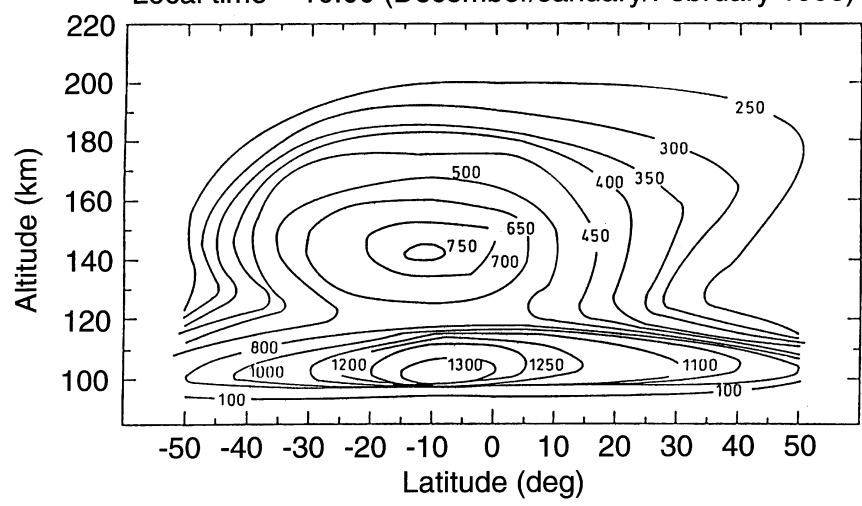

Fig. 6. The latitudinal variation of three monthly (December 1992/ January/February 1993) averaged volume emission rates as obtained from present model at $10 \mathrm{~h}$ local time

observed values and therefore outer contours are not closed as is found from WINDII data. If the calculated emission rates are reduced by a factor of about 1.7 then one can reproduce the WINDII morphology in the region between 98 and $120 \mathrm{~km}$. Since three body recombination of atomic oxygen is the main source of $\mathrm{O}\left({ }^{1} \mathrm{~S}\right)$ between 90 and $98 \mathrm{~km}$ and only involves oxygen densities in the calculation, it is quite likely, therefore that discrepancy in this region between measured and modelled emission rates may be due to failure of MSIS90 model to reproduce the oxygen densities in this region (Singh et al., 1996). A close examination of these figures reveals that the average calculated mesospheric peak (region of maximum emission rate) is located between $15^{\circ} \mathrm{S}$ and $0^{\circ}$ latitudes, while average observed peak is located between $10^{\circ} \mathrm{S}$ and $0^{\circ}$ latitudes. The calculated average thermospheric peak (region of maximum emission rate) is found at about $140 \mathrm{~km}$ and is located between $10^{\circ} \mathrm{S}$ and $15^{\circ} \mathrm{S}$ latitudes. Although the measured thermospheric peak is found more or less at the same altitude as that of modelled one it is located between $15^{\circ} \mathrm{S}$ and $30^{\circ} \mathrm{S}$.

Figures 7 and 8 show the comparison between measured and modelled volume emission rates for the

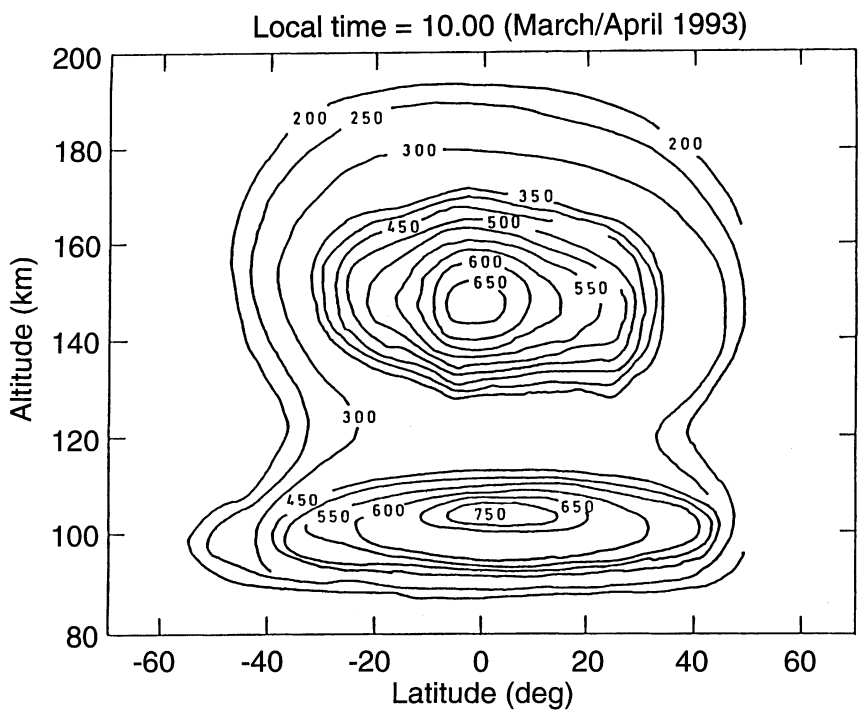

Fig. 7. The latitudinal variation of two monthly (March/April 1993) averaged volume emission rates as measured by wind imaging interferometer (WINDII) at $10 \mathrm{~h}$ local time (courtesy of Prof. G. G. Shepherd, York University, Canada)

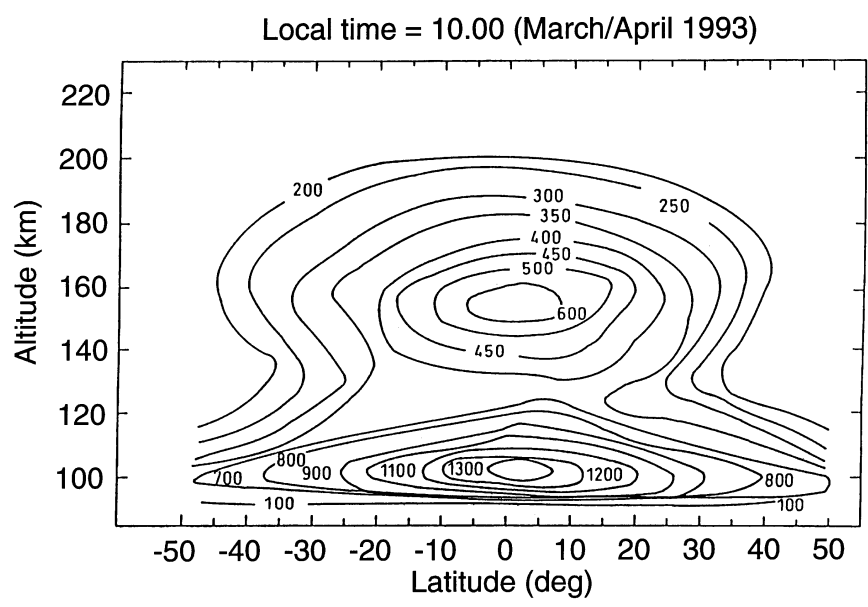

Fig. 8. The latitudinal variation of two monthly (March/April 1993) averaged volume emission rates as obtained from present model at $10 \mathrm{~h}$ local time

months of March/April 1993 at $10 \mathrm{~h}$ local time. It is noticeable from these that the modelled morphology is in good agreement in thermospheric region while a discrepancy exists in the region between $98-120 \mathrm{~km}$ where calculated emission rates are substantially larger than the observed values. The calculated latitudinal spread of thermospheric and mesospheric peaks is found more or less at the same location as is found from WINDII data. At this juncture it is extremely difficult to explain the latitudinal discrepancy between modelled and observed mesospheric and thermospheric peaks for the months of December 1992/January/February 1993. Consequently, we would only suggest that one may include some of the processes such as transport of atomic oxygen and tidal effects in the present model and see their effects on these peaks. The tidal effects have been found prominent for this emission in nightglow 
(Shepherd et al., 1995) and one may also study tidal effects on the day glow emission. The analysis of the tidal effects goes beyond the scope of this study but will be the subject of a more comprehensive analysis of the full WINDII greenline dayglow database.

\section{Conclusions}

The morphology of $\mathrm{O}\left({ }^{1} \mathrm{~S}\right)$ dayglow emission has been presented. The updated glow model has been used to obtain the volume emission rates of greenline dayglow emission. A comparison between the modelled and WINDII observation has been made for the only available data for two cases December 1992/January/ February 1993 and March/April 1993 at 10 h local time. The morphology obtained from the model is found to be in reasonably good agreement with WINDII observation at thermospheric altitudes (above $120 \mathrm{~km}$ ). In the lower thermosphere and upper mesosphere the modelled emission rates are about a factor of 1.7 times higher than the measured values. This discrepancy has been discussed in terms of scaling of solar fluxes which accounts for the solar activity for the day on which calculations are made. Further, it is suggested that the transport of atomic oxygen and tidal effects in the model may be considered and see if any effect is found on the emission rates.

Acknowledgements. The authors thank Prof. G. G. Shepherd and Prof. I. C. McDade, York University, Canada, for providing the WINDII data. One of us (ST) thanks UGC, New Delhi, for financial support.

Topical Editor F. Vial thanks R. A. Akmaev and R. G. Roble for their help in evaluating this paper.

\section{References}

Abreu, V. J., and J. H. Yee, Quenching of $\mathrm{N}_{2}(\mathrm{~A})$ by $\mathrm{O}$ as a mechanism of $\mathrm{O}\left({ }^{1} \mathrm{~S}\right)$, International Union of Geodesy and Geophysics, XX General Assembly, Vienna, Austria, August, Abstr. P179, 1991.

Akmaev, R. A., and G. M., Shved, Modelling of the composition of the lower thermosphere taking account of the dynamics with application of tidal variation of the (OI) 5577A airglow, J. Atmos. Terr, Phys., 42, 705, 1980.

Banks, P. M., and A. F. Nagy, Concerning the influence of elastic scattering upon photoelectron transport and escape, J. Geophys, Res., 75, 1902, 1970.

Barth, C. A., Three body reactions, Ann. Phys., 5, 329, 1964.

Bates, D. R., Oxygen green and red line emission and $\mathrm{O}_{2}^{+}$ dissociative recombination, Planet. Space Sci., 28, 108, 1998.

Bates, D. R., and E. C. Zipf, The $\mathrm{O}\left({ }^{1} \mathrm{~S}\right)$ quantum yield from $\mathrm{O}_{2}^{+}$ disoociative recombination, Planet. Space Sci., 28, 1081, 1980.

Bilitza, D., IRI: recent developments, Radio Sci., 21, 343, 1986.

Feldman, P. D., J. P. Doering, and E. C. Zipf, Excitation of $\mathrm{O}\left({ }^{1} \mathrm{~S}\right)$ atoms in the day airglow, J. Geophys. Res., 76, 3087, 1971.

Frederick, J. E., D. W. Rusch, G. A. Victor, W. E. Sharp, P. B. Haya and H. C. Brinton, The OI(15500A) airglow: observations and excitation mechanisms, J. Geophys. Res., 81, 3923, 1976.

Guberman, S. L., The production of $\mathrm{O}\left({ }^{1} \mathrm{~S}\right)$ from dissociative recombination of $\mathrm{O}_{2}^{+}$, Nature, 327, 408, 1987.

Gattinger, R. L., F. R. Harris, and A. Vallance Jones, The height, spectrum and mechanism of type-B red aurora and its bearing on the excitation of $\mathrm{O}\left({ }^{1} \mathrm{~S}\right)$ in the aurora, Planet. Space Sci., 33, 207, 1985.
Hays, P. B., and W. E. Sharp, Twilight airglow, 1, Photoelectrons and [OI] 5577 Angstrom radiation, J. Geophys Res., 78, 1153, 1973.

Hays, P. B., G. R. Curignan, B. C. Kennedy, G. G. Shepherd, and J. C. G. Walker, The visible-airglow experiment on Atmosphere Explorer, Radio Sci., 8, 369, 1973.

Hedin, A. E., Extension of the MSIS thermosphere model into the middle and lower atmosphere, J. Geophys. Res., 96, 1159, 1991.

Hinteregger, H. E., EUV flux variation during end of solar cycle 20 and begining solar cycle 21 observed from AE-C satellite, Geophys. Res. Lett., 4, 231, 1977.

Kanik, I., S. Trajmar, and J. C. Nickel, Total electron scattering and electronic state excitation cross sections for $\mathrm{O}_{2}, \mathrm{CO}$ and $\mathrm{CH}_{4}$, J. Geophys. Res., 98, 7447, 1993.

Kenner, R. D., and E. A. Ogryzlo, A direct determination of the rate constant for the quenching of $\mathrm{O}\left({ }^{1} \mathrm{~S}\right)$ by $\mathrm{O}_{2}\left(\mathrm{a}^{1} \Delta_{\mathrm{g}}\right), J$. Photochem., 18, 379, 1982.

Laher, R. R., and F. R. Gilmore, Updated excitation and ionization cross sections for electron impact on atomic oxygen, J. Phys. Chem. Ref. Data, 19, 277, 1990.

Lawrence, G. M., and M. J. Ewan, Production of $\mathrm{O}\left({ }^{1} \mathrm{~S}\right)$ from photodissociation of $\mathrm{O}_{2}, J$. Geophys. Res., 78, 8314, 1973.

McDade, I. C., E. J. Lewellyn, and B. H. Solheim, A rocket measurement of $\mathrm{O}\left({ }^{1} \mathrm{~S}\right)$ and $\mathrm{N}_{2}$ emission in a pulsating aurora, Can. J. Phys., 63, 983, 1985.

McDade, I. C., D. P. Murtagh, R. G. H. Greer, P. H. G. Dickinson, G, Witt, J. Stegman, E. J. Lewellyn, L. Thomas, and D. B. Jenkins, ETON 2: quenching parameters for the proposed precursors of $\mathrm{O}_{2}\left(\mathrm{~b}^{1} \Sigma_{\mathrm{g}}\right)$ and $\mathrm{O}\left({ }^{1} \mathrm{~S}\right)$ in the terrestrial nightglow, Planet. Space Sci, 34, 789, 1986.

Nagy, A. F., and P. M. Banks, Photoelectron fluxes in the ionosphere, J. Geophys. Res., 75, 6261, 1970.

Nardi, B., An inversion technique to recover lower thermospheric winds from space-borne remote measurements of (OI) $5577 \mathrm{~A}$, $\mathrm{PhD}$ Thesis, The University of Michigan, USA, 1991.

Nicolaides, C., O. Sinanoglu, and P. Westhouse, Theory of atomic structure including electron correlation. IV. Method for forbidden transition probabilities with results for [OI], [OII], [OIII], [NI], [NII] and [CI], Phys. Rev., A4, 1400, 1971.

Piper, L. G., The excitation of $\mathrm{O}\left({ }^{1} \mathrm{~S}\right)$ in the reaction between $\mathrm{N}\left(\mathrm{A}^{3} \Sigma_{\mathrm{u}}^{+}\right)$and $\mathrm{O}\left({ }^{3} \mathrm{p}\right), J$. Chem. Phys., 77, 2373, 1982.

Piper, L. G., G. E. Caledonia, and J. P. Kennelly, Rate constants for deactivation of $\mathrm{N}_{2}\left(\mathrm{~A}^{3} \Sigma_{\mathrm{u}}^{+}\right), v=0,1$ by $\mathrm{O}, J$. Chem. Phys., 75, 2847, 1981.

Richards, P. G., and D. G. Torr, A simple theoretical model for calculating and parametrizing the ionospheric photoelectron flux, J. Geophys. Res., 88, 2155, 1983.

Solomon, S, Glow model version 0.95, LASP, University of Colorado, Boulder USA, 1992.

Shepherd, G. G., G. Thuillier, W. A. Gault, G. H. Solheim, C. Hersom, J. M. Alunni, J. -F. Brun, S. Brun, P. Charlot, L. L. Cogger, D. -L. Desauliniers, W. F. J. Evans, F. Girod, R. L. Gattinger, D. Harvie, R. H. Hum, D. J. W. Kendall, E. J. Liewellyn, R. P. Lowe, J. Ohrt, F. Pasternak, O. Peillet, I. Powell, Y,. Rochon, W. E. Ward, R. H. Wiens, and J. Wimperis, WINDII, the Wind Imaging Interferometer on the Upper Atmosphere Research Satellite, J. Geophys., Res, 98, 10725, 1993.

Shepherd, G. G. McLandress, and B. H. Solheim, Tidal influence on $\mathrm{O}\left({ }^{1} \mathrm{~S}\right)$ airglow emission rate distributions at the geographic equator as observed by WINDII, Geophys. Res. Lett., 22, 275, 1995.

Solheim, B. H., W. E. Ward, V. Singh, and G. S. Shepherd, The morphology of the daytime greenline emission as observed with the Wind Imaging Interferometer (WINDII) on UARS, EOS, Trans., 74, 473, 1993.

Singh, V. and S. Tyagi, Study of $\mathrm{O}\left({ }^{1} \mathrm{~S}\right)$ dayglow emission near equatorial latitudes, Indian J. Radio Space Phys., 26, 36, 1997.

Singh, V, I. C. McDade, G. G. Shepherd, B. H. Solheim, and W. E. Ward, The $\mathrm{O}\left({ }^{1} \mathrm{~S}\right)$ dayglow emission as observed by the WIND imaging interferometer on the UARS, Ann. Geophysicae, 14, 637,1996 
Slanger, T. G., and G. Black, $\mathrm{O}\left({ }^{1} \mathrm{~S}\right)$ quenching by $\mathrm{O}\left({ }^{3} \mathrm{P}\right)$, J. Chem, Phys., 64, 3767, 1976.

Slanger, T. G., B. J. Wood and G. Black, The temperature dependence of $\mathrm{O}\left({ }^{1} \mathrm{~S}\right)$ quenching by $\mathrm{O}_{2}$, Chem. Phys. Lett., 17, 401, 1972.

Trajmar, S., D. F. Register, and A. Chutjian, Electron scattering by molecules II. Experimental methods and data, Phys. Rep., 97, 219, 1983

Takahashi, H., B. R. Clemesha, P. P. Batista, Y. Sahai, M. A. Abdu, and Murlikrishna, Equatorial F-region OI $6300 \mathrm{~A}$ and OI 5577 A emission profiles observed by rocket-borne airglow photometer, Planet. Space Sci., 32, 897, 1990.

Torr, M. R., and D. G. Torr, Ionization frequencies for solar cycle 21: revised, J. Geophys. Res., 90, 6675, 1985.

Torr, D. G., M. R. Torr, and P. G. Richards, Thermospheric airglow emission: a comparison of measurements from ATLAS1 and theory, Geophys. Res. Lett., 20, 519, 1993.
Wallace, L., and M. B. McElroy, The visual dayglow, Planet. Space Sci., 14, 667, 1966.

Walls, F. L., and G. H. Dunn, Measurement of total cross sections for electron recombination with $\mathrm{NO}^{+}$and $\mathrm{O}_{2}^{+}$using ion storage techniques, J. Geophys. Res., 79, 1911, 1974.

Yee, J. H., and T. L. Killeen, Thermospheric production of $\mathrm{O}\left({ }^{1} \mathrm{~S}\right)$ by dissociative recombination of vibrationally excited $\mathrm{O}_{2}$, Planet. Space Sci., 34, 1101, 1986.

Yee, J. H., V. J. Abreu, and W. B. Colwell, Aeronomical determination of $\mathrm{O}\left({ }^{1} \mathrm{~S}\right)$ and $\mathrm{O}\left({ }^{1} \mathrm{D}\right)$ from dissociative recombination of $\mathrm{O}_{2}^{+}$, in Dissociative Recombination, Theory, Experiment and Application, Eds. J.B.A. Mitchell, and S.L. Guberman, World Scientific, New Jersey, 1989.

Zipf, E. C., The excitation of $\mathrm{O}\left({ }^{1} \mathrm{~S}\right)$ by the dissociative recombination of $\mathrm{O}_{2}^{+}$ions: electron temperature dependence, Planet. Space Sci., 36, 621, 1988. 